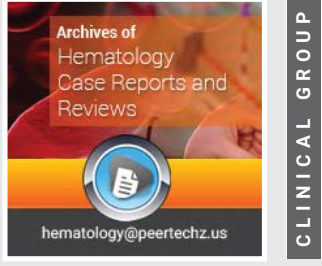

\title{
Triclonal gammopathy in a patient with smoldering Plasma Cell Myeloma (PCM)*
}

\author{
Myrlande Maingrette ${ }^{1 *}$ and Vikram Palamalai ${ }^{2}$ \\ ${ }^{1}$ Summa Health System, Student in an Organized Health Care Education/Training Program in Akron, \\ Ohio, USA \\ ${ }^{2}$ Department of Laboratory Medicine and Pathology, University of Minnesota, Minneapolis, MN, USA
}

Received: 26 June, 202

Accepted: 16 July, 2021

Published: 17 July, 2021

*Corresponding author: Dr. Myrlande Maingrette, Summa Health System, Student in an Organized Health Care Education/Training Program in Akron, Ohio, USA, Tel: 4259317300; E-mail:medimeters@gmail.com, maingrettem@summahealth.org

https://www.peertechzpublications.com

\section{Check for updates}

\section{Abstract}

Objective: Triclonal gammopathies, although considered a variant of monoclonal gammopathy of unknown significance, have been shown to be associated with other malignancies and inflammatory pathologies. There is sadly a paucity of triclonal gammopathies reported in the literature. Here, we present a case diagnosed with triclonal gammopathy/ MGUS to add to the small body of knowledge available about this rare condition.

Methods: Review of the case history and laboratory investigations.

Results: The case history and progression of disease of an 86 year old female diagnosed with triclonal gammopathy/ MGUS (by capillary electrophoresis and immunosubtraction), smoldering plasma cell myeloma, progressive paraproteinemia and worsening renal and hepatic functions and yet no detected bone marrow plasma cell clonality is described with relevant clinical investigations.

Conclusion: Given the rarity of triclonal gammopathies, currently available research has yet to establish whether they arise from one clone or three unrelated clones of immunoglobulins. We discussed a case of triclonal gammopathy without any detected bone marrow plasma cell clonality. Increased awareness of this disorder and its associated analytical difficulties can help in the formulation of future guidelines for their analysis and treatment, as more cases are catalogued.

\section{Introduction}

Plasma Cell Myeloma (PCM), a neoplasm of B cell lineage with excessive proliferation of abnormal plasma cells [1], is defined as clonal bone marrow plasma cells greater than or equal to $10 \%$ or biopsyproven bony or extramedullary plasmacytoma PLUS one or more evidence of end organ damage such as hypercalcemia, renal insufficiency, anemia, one or more osteolytic lesions [2]. PCM and its variants account for $10 \%$ of hematological malignancies and are part of a spectrum of neoplastic plasmacytic disorders (Table 1). The clinical variants of PCM include smoldering PCM, nonsecretory myeloma and plasma cell leukemia. Frank PCM or its variants can be debilitating.

Frank PCM is diagnosed by integrated interpretations of clinical, laboratory, radiologic, morphologic and immunophenotypic features. Salient diagnostic features include:
Table 1: Common Neoplastic Plasmacytic Disorders [3].

\begin{tabular}{|c|c|}
\hline DISORDER & $\begin{array}{l}\text { ORGANS COMMONLY } \\
\text { INVOLVED }\end{array}$ \\
\hline Monoclonal or Polyclonal Plasmacytosis & Peripheral blood, bone marrow \\
\hline $\begin{array}{c}\text { Monoclonal Gammopathy of Uncertain } \\
\text { Significance (MGUS) }\end{array}$ & Peripheral blood, bone marrow \\
\hline $\begin{array}{c}\text { Plasma Cell Myeloma (PCM) and clinical } \\
\text { variants Clinical Variants: } \\
\text { Smoldering PCM } \\
\text { Nonsecretory myeloma } \\
\text { Plasma cell Leukemia }\end{array}$ & $\begin{array}{l}\text { Bone (lesions), peripheral blood, } \\
\text { bone marrow }\end{array}$ \\
\hline
\end{tabular}

Monoclonal immunoglobulin deposition disease (amyloidosis)

Lymphoplasmacytic Lymphoma

Osteosclerotic Myeloma

Peripheral blood, bone marrow

Peripheral blood, bone marrow, lymph nodes

Peripheral blood, bone marrow

Heavy chain diseases ( gamma, mu, alpha)
Peripheral blood, bone marrow, liver, spleen 
- The presence of $M$-protein in the serum or urine

- bone marrow monoclonal plasma cells usually $>10 \%$, or plasmacytoma

- myeloma /plasmacytoma -related end organ damage [3].

Smoldering PCM, referred sometimes as asymptomatic PCM, is distinguished from frank PCM by its lack of end-organ damage. Smoldering PCM is often diagnosed in persons who meet the following criteria:

- Serum Monoclonal (M) protein $\geq 3 \mathrm{~g} / \mathrm{dL}$ and/or $10-60$ percent bone marrow clonal plasma cells.

- Absence of lytic bone lesions, anemia, hypercalcemia, or renal insufficiency (end-organ damage) that can be attributed to the plasma cell proliferative disorder and the absence of biomarkers associated with near inevitable progression to end-organ damage [2].

Monoclonal Gammopathy Of Uncertain Significance (MGUS), a disorder on the spectrum of neoplastic plasmacytic disorders (Table 1), is a premalignant precursor lesion to the development of frank PCM [3]. A small fraction of MGUS, about $1 \%$ per year, evolve to frank PCM, amyloidosis, or other neoplastic plasmacytic disorders [3]. MGUS is distinguished from PCM based on the quantity of the Monoclonal $(\mathrm{M})$ protein and the percentage of plasma cells in the bone marrow. MGUS requires three criteria for diagnosis:

-serum monoclonal protein $<30 \mathrm{~g} / \mathrm{dL}$,

-bone marrow plasma cells $<10 \%$,

-and absence of myeloma defining events, amyloidosis or Waldenstrom macroglobulinemia [2].

Although in some cases PCM can arise from MGUS and they can occur together, each entity when presenting alone, requires a different therapeutic approach. Therefore distinguishing between them portends significant clinical implications. Serum Protein Electrophoresis (SPEP) should be done to evaluate general manifestations like malaise, weakness, chronic bone pain and anemia, to quantify the monoclonal protein, and detect the correct gammopathy in these patients [4].

Capillary Electrophoresis(CE), the serum protein separation technique used in our lab, typically "consists of a fused silica capillary, two electrolyte buffer reservoirs, a high-voltage power supply, and a detector linked to a data acquisition unit. The sample is introduced into the capillary inlet. When a high voltage is applied across the capillary ends, the sample molecules are separated by electro-osmotic flow. A bulk flow results from excess positive ions at the inner capillary surface moving toward the cathode. The positive ions in the specimen emerge early at the capillary outlet because the electroosmotic flow and the ion movement are in the same direction. Negative ions in the specimen also move toward the capillary outlet but at a slower rate. As the sample ions migrate toward the capillary outlet, different types of detectors, including optical, conductivity, electrochemical, mass spectroscopy, or radioactivity detectors, are used to detect and measure them... Advantages of CE over conventional electrophoresis are its short analytic time, improved resolving power, and microsample volumes" [5]. Different fractions of serum proteins are separated into five bands - albumin, alpha-1, alpha-2, beta, and gamma globulin fractions. Most monoclonal proteins are identified primarily in the gamma fraction, some in the beta fraction and a few are rarely seen in the alpha- 2 region.

Many conditions can cause an increase in the gamma region; those that cause a homogenous spike/peak are of special interest. These peaks, suggestive of monoclonal gammopathies, result from the proliferation of a single, usually malignant clone of plasma cells which produces either a single class of intact immunoglobulins, heavy chains, light chains or both. These protein chains are para proteins or $\mathrm{M}$ (monoclonal) proteins. Neoplastic plasmacytic disorders are the most common causes of paraproteinemia [1].

Monoclonal and biclonal gammopathies are identified by electrophoresis at the time of diagnosis. Rare and relatively unknown, a triclonal gammopathy is an immunoglobulin abnormality in which three discrete monoclonal subpopulations of immunoglobulin molecules are present in the patient's serum. In triclonal gammopathies, the increases in immunoglobulins from one, two, or three separate clonal processes may confer increased risk of malignancy, or unfavorable disease progression [4].

\section{Case history}

In this paper, we present a case of an 86-year-old female who in 2015, following hematologic consult at an outside institution was diagnosed with MGUS . Labs from April 2015 revealed IgA levels at $2310 \mathrm{mg} / \mathrm{dL}$ and IgM at $256 \mathrm{mg} / \mathrm{dL}$. Reflex Immunofixation Electrophoresis ( IFE) showed monoclonal IgA kappa $1.57 \mathrm{~g} / \mathrm{dL}$, serum free kappa light chains $3.76 \mathrm{mg} /$ $\mathrm{dL}$, lambda light chain $2.44 \mathrm{mg} / \mathrm{dL}$. Other lab values revealed Blood Urea Nitrogen (BUN) $36 \mathrm{mg} / \mathrm{dL}$, creatinine (Cr) $0.75 \mathrm{mg} /$ $\mathrm{dL}$, calcium $10.2 \mathrm{mg} / \mathrm{dL}$. Skeletal survey was negative for lytic lesions.

She was subsequently lost to follow-up until June 2019 when she reported fatigue, low mood, anxiety, and sleep disturbance. She denied fevers, night sweats, weight changes, bone pain, or changes in mental status. Further evaluation revealed hepatic steatosis, hyperlipidemia, retroperitoneal adenopathy, right kidney calculus, right hydronephrosis and chronic renal insufficiency by creatinine elevation to $2.37 \mathrm{mg} /$ dL .

Electrophoresis showed two large bands. Reflex IFE showed two distinct large monoclonal IgA Kappa bands. Serum calcium was $10.7 \mathrm{mg} / \mathrm{dL}$. There was no anemia. Following nephrology consult, Lisinopril was discontinued, and her creatinine normalized to $1.25 \mathrm{mg} / \mathrm{dL}$ as did her calcium to $10.2 \mathrm{mg} / \mathrm{dL}$. Skeletal survey showed no lytic lesions. Urine IFE at the time showed monoclonal IgA heavy chain with associated kappa 

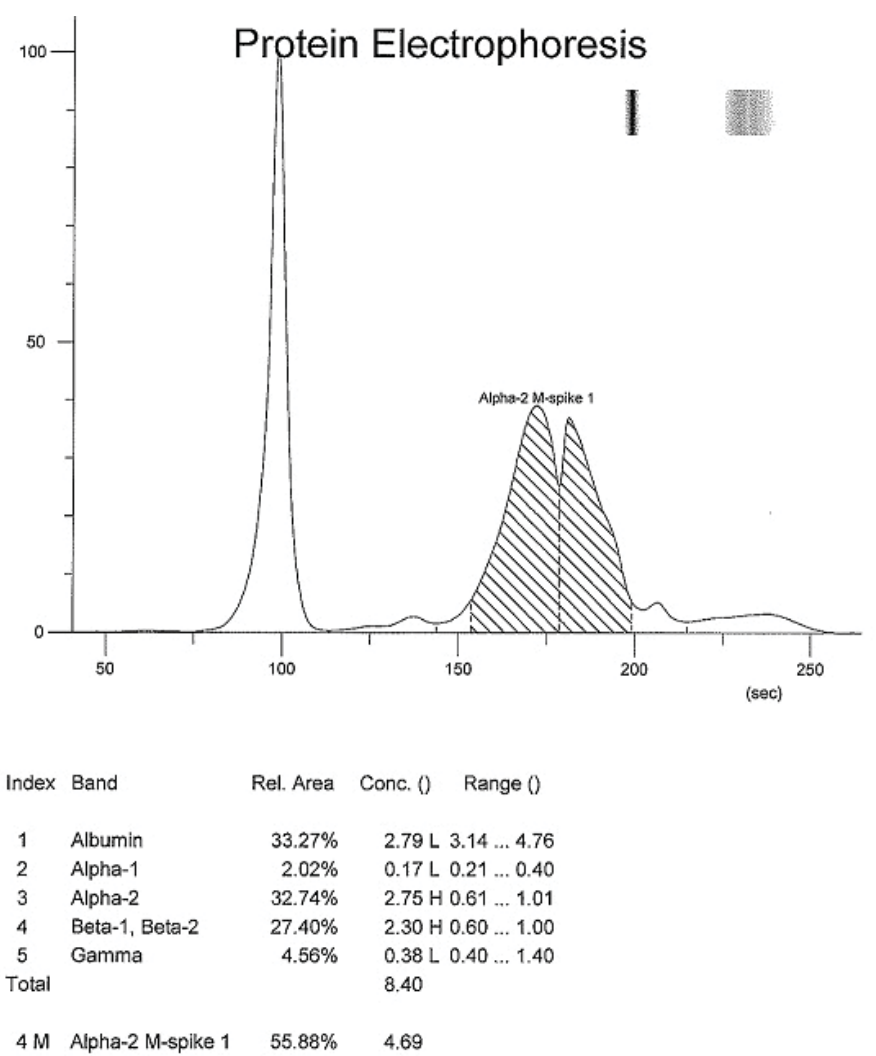

Figure 1: Capillary Protein Electrophoresis 10/2020. Two large bands in the alpha-2 region and at the alpha-2 - beta junction. Both fractions are significantly elevated.
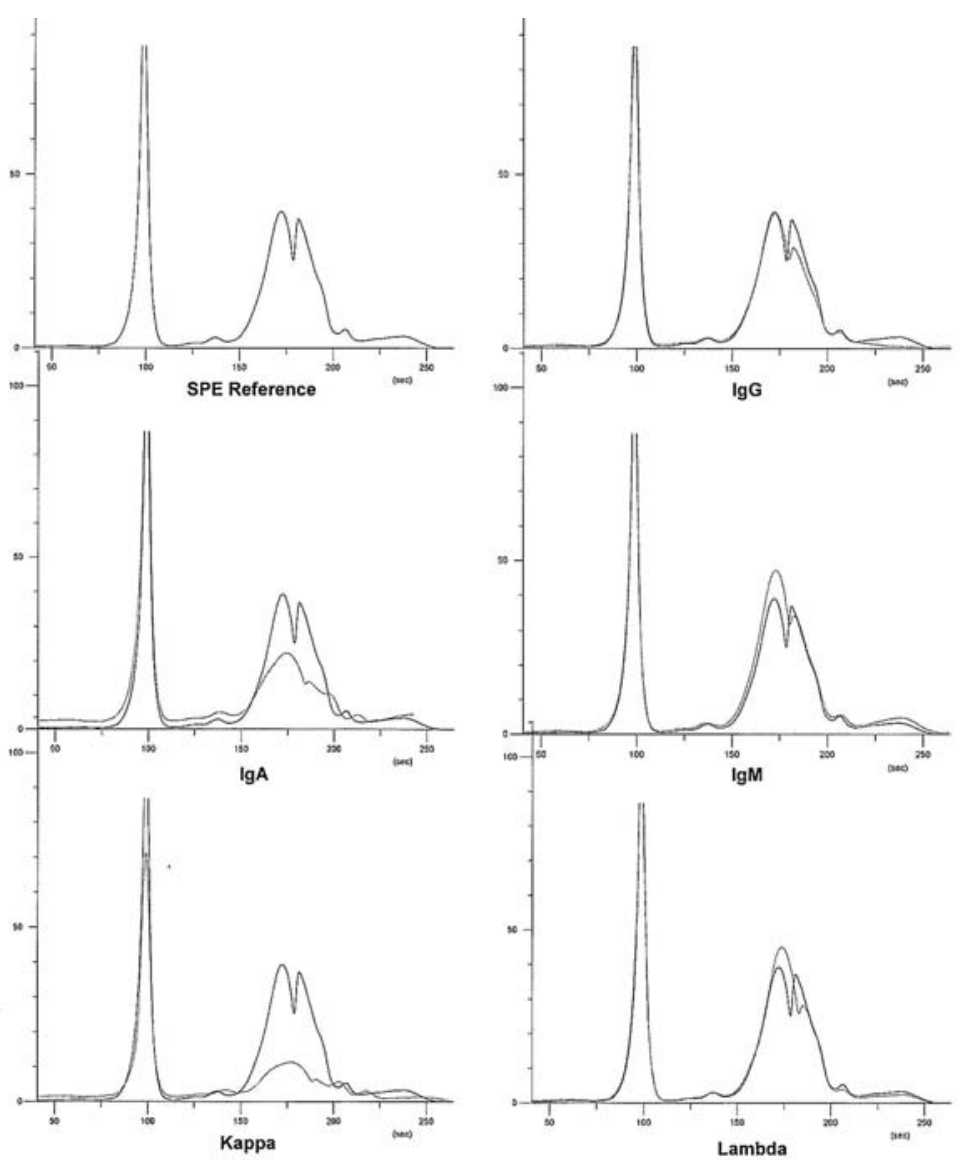

Figure 2: Reflex Immunofixation Electrophoresis (IFE) 10/2020. Diagrams show substantial elevation in IgA and kappa light chains; there is also mild increase in lambda light chains.

Citation: Maingrette M, Palamalai V (2021) Triclonal gammopathy in a patient with smoldering Plasma Cell Myeloma (PCM)*. Arch Hematol Case Rep Rev 6(1): 013-017. DOI: https://dx.doi.org/10.17352/ahcrr.000032 
light chain and excess monoclonal free kappa light chain. With these new findings, she was diagnosed with multiple myeloma. Complete staging required a bone marrow biopsy which the patient declined at that time. She however agreed to periodic hematologic monitoring, every three months. Given that she remained asymptomatic in regards to the myeloma - with stable kidney function, calcium levels, and no anemia - her diagnosis was left at smoldering multiple myeloma/plasma cell myeloma.

Follow up surveillance CE in October 2019 revealed increased IgA level of $3620.7 \mathrm{mg} / \mathrm{dL}$ and three distinct bands in the alpha-2 and beta regions. IFE showed increase in IgA kappa light chains $(176.31 \mathrm{mg} / \mathrm{dL})$ and increase in IgA lambda free light chains (154.66 mg/dL) (Figures 1- 3, Table 2). Complete blood counts at the time, revealed no anemia, mild lymphocytosis $(42.8 / \mu \mathrm{L})$ and no abnormality in platelets. A complete metabolic panel revealed normal calcium, elevated creatinine $(1.52 \mathrm{mg} /$ $\mathrm{dL}$ ), slight elevation in aspartate aminotransferase (AST 63 U/L), normal Alkaline Phosphatase (ALP) and normal alanine Aminotransferase (ALT) levels. Also noted were elevated total protein $(8.4 \mathrm{~g} / \mathrm{dL})$, hypoalbuminemia $(2.8 \mathrm{~g} / \mathrm{dL})$, elevation in alpha-2 globulin $(2.8 \mathrm{~g} / \mathrm{dL})$, elevation in beta globulin $(2.3$ $\mathrm{g} / \mathrm{dL}$ ), normal gamma globulin, and evidence of suppression of the polyclonal immunoglobulin IgG, lowered to $572.8 \mathrm{mg} /$ dL. There were no worrisome symptoms of overt end organ damage. The patient continued to refuse bone marrow biopsy.

In the fall of 2020, she developed stage $3 /$ stage 4 chronic kidney disease and agreed to a bone marrow biopsy. Bone marrow biopsy, performed in November 2020, revealed cellular marrow with tri-lineage maturing hematopoiesis, erythroid hyperplasia and $5 \%$ plasma cells. In situ hybridization detected no plasma cell clonality. Follow-up cytogenetic study revealed no detectable chromosomal abnormality. No pharmacologic interventions were taken. She remained on continued periodic observation.

\section{Discussion}

Here, we presented a case of an 86 year old female diagnosed with triclonal gammopathy/ MGUS, smoldering plasma cell myeloma, progressive paraproteinemia (Table 2), worsening renal and hepatic functions and yet no detected bone marrow plasma cell clonality and no documented extramedullary lymphoproliferation.

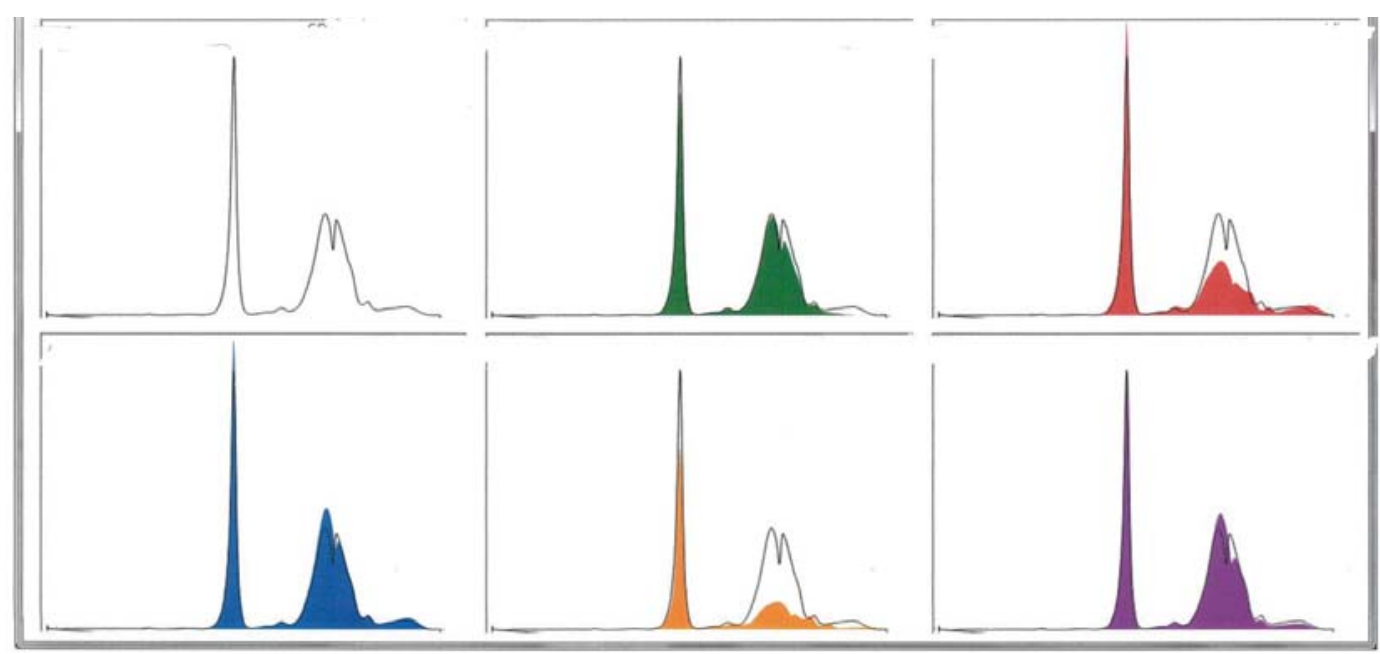

Figure 3: IFE - 10/2020. Spatial representations of substantial elevation in IgA and kappa light chains and mild increase in lambda light chains.

Table 2: Monoclonal proteins by capillary electrophoresis over time [3].

\begin{tabular}{|c|c|c|c|c|c|c|}
\hline & Ref. Range & $11 / 7 / 2019$ & $1 / 30 / 2020$ & $5 / 27 / 2020$ & $10 / 15 / 2020$ & $1 / 21 / 2021$ \\
\hline $\lg A$ & $70.0-400.0 \mathrm{mg} / \mathrm{dL}$ & $4130.9(\mathrm{H})$ & $3714.7(\mathrm{H})$ & $4255.5(\mathrm{H})$ & $3620.7(H)$ & $3054.1(\mathrm{H})$ \\
\hline Total lgG & $700.0-1600.0 \mathrm{mg} / \mathrm{dL}$ & $519.1(\mathrm{~L})$ & $501.6(\mathrm{~L})$ & $470.4(\mathrm{~L})$ & $572.8(\mathrm{~L})$ & $528.2(\mathrm{~L})$ \\
\hline $\lg M$ & $40.0-230.0 \mathrm{mg} / \mathrm{dL}$ & 137.1 & 126.0 & 111.7 & 116.5 & 94.1 \\
\hline Alpha 2 Globulin & $0.5-1.0 \mathrm{~g} / \mathrm{dL}$ & $2.9(\mathrm{H})$ & $0.1(\mathrm{~L})$ & $3.2(\mathrm{H})$ & $2.8(H)$ & $1.9(H)$ \\
\hline $\begin{array}{l}\text { Alpha-1- } \\
\text { Globulin }\end{array}$ & $0.2-0.4 \mathrm{~g} / \mathrm{dL}$ & 0.2 & $0.1(\mathrm{~L})$ & 0.2 & 0.2 & 0.2 \\
\hline $\begin{array}{c}\text { Kappa Free } \\
\text { Light } \\
\text { Chains }\end{array}$ & $3.30-19.40 \mathrm{mg} / \mathrm{L}$ & $5.50(\mathrm{H})$ & $5.19(\mathrm{H})$ & $97.47(\mathrm{H})$ & $176.31(\mathrm{H})$ & $185.95(\mathrm{H})$ \\
\hline $\begin{array}{l}\text { Lambda } \\
\text { Free Light } \\
\text { Chains }\end{array}$ & $5.71-26.30 \mathrm{mg} / \mathrm{L}$ & $4.46(\mathrm{H})$ & $6.88(H)$ & $106.59(\mathrm{H})$ & $154.66(H)$ & $189.30(\mathrm{H})$ \\
\hline Monoclonal protein* & & $2.11 \mathrm{~g} / \mathrm{dL}$ & $3.02 \mathrm{~g} / \mathrm{dL}$ & $3.44 \mathrm{~g} / \mathrm{dL}$ & $4.69 \mathrm{~g} / \mathrm{dL}$ & $4.49 \mathrm{~g} / \mathrm{dL}$ \\
\hline
\end{tabular}

(Note: IgA, alpha2 globulins, Kappa and Lambda free light chains have remained significantly above normal levels at all times; IgG has remained suppressed). 
The clinical significance of these findings is unknown. There are suspicions that patients with triclonal gammopathy may experience a less favorable course of disease than those with monoclonal gammopathy. One study reports a slight risk (2-10\%/ year) of developing plasma cell myeloma or another malignant monoclonal gammopathy in patients with MGUS [1]. Given that MGUS is asymptomatic and is not routinely screened for in clinical practice, diagnosing and managing it can be challenging. Accurate disease monitoring is critical in the disease course, during, and after therapy - to confirm achievement of complete remission, or to detect early relapse before the occurrence of end organ damage [6].

Although triclonal gammopathies are considered a variant of MGUS, they can also be associated with other malignancies and inflammatory pathologies. There is one reported case of triclonal gammopathy in a relapsing multiple myeloma patient resistant to therapy, suggesting that more than one monoclonal protein may be a negative prognostic factor [6]. Grosbois et al report that only 26 cases of triclonal gammopathies have been reported in the literature. Sixteen of these cases are associated with lymphoproliferative or hemoproliferative malignancies sooner or later [7]. In the case presented here, diagnostic categorization would remain no worse than smoldering PCM with triclonal gammopathy, in a patient with some evidence of end organ damage such as chronic renal failure and hepatic steatosis, without anemia, hypercalcemia, lytic bone lesions, or detectable clonal plasma cells.

Other differentials considered included benign gammopathy, Waldenstrom macroglobulinemia, and frank plasma cell myeloma; although this is by no means an exhaustive list. Waldenstrom macroglobulinemia, an IgM monoclonal gammopathy generally associated with an IgM level of $>3 \mathrm{~g} / \mathrm{dL}$ and at least one lymphoproliferative disorder, presents with its hallmarks of anemia and hyperviscosity [8]. The case presented here shows unremarkable IgM levels, absence of hyperviscosity, absence of anemia; Waldenstrom macroglobulinemia remains unlikely. This case also lacks clonal lymphoproliferation, lytic bone lesions, or hypercalcemia, hence frank PCM cannot be established. Smoldering PCM thus remains a better fitting diagnosis.

The behavior of the multi clonal gammopathies is not easy to predict. Biclonal gammopathies made up of IgM and IgG components may behave primarily like a Waldenstrom macroglobulinemia or multiple myeloma or have features of both conditions. Moreover, one $\mathrm{M}$ protein gammopathy may have a benign course, while another progresses to a malignant course. Choosing the appropriate therapy in these cases may be difficult, and no clear guidelines are available $[9,10]$.

\section{Conclusion}

Given the rarity of triclonal gammopathies, currently available research has yet to establish whether they arise from one clone or three unrelated clones of immunoglobulins. Triclonal gammopathies can present substantial challenges to the clinical and laboratory staff. As more cases are catalogued, the increased awareness of this disorder and its associated analytical difficulties can help in the formulation of future guidelines for their diagnosis and treatment.

*In this paper, Plasma Cell Myeloma (PCM) is used interchangeably with multiple myeloma (which was the former designation).

\section{Disclosures}

Patient privacy protection: The data reported in this paper is in adherence with IRB policies, has been reviewed and approved by IRB , ensuring the patient's privacy was protected by the proper de-identification of the case.

\section{References}

1. Sunita T (2012) The Role of Serum Protein Electrophoresis in the Detection of Multiple Myeloma: An Experience of a Corporate Hospital. J Clin Diagn Res 6 : 1458-1461. Link: https://bit.ly/3xM8pvx

2. Rajkumar S (2020) Smoldering Multiple Myeloma. UPTO DATE. Link: https://bit.ly/2Uk1hlv

3. Czuchlewski FR (2010) Plasma Cell Myeloma and Other Immunosecretory Neoplasms, Chapter 23. Bone Marrow Pathology, $3^{\text {rd }}$. Edition. 2010.

4. Kyle R, Rajkumar SV (2005) Monoclonal Gammopathy of Undetermined Significance - Comprehensive Review. Clinical Lymphoma \& Myeloma 6: 102 114. Link: https://bit.ly/3ia9jvq

5. McPherson RA, Pincus MR (2021) Henry's Clinical Diagnosis and Management by Laboratory Methods, $23^{\text {rd }}$. Edition Chapter 4: 33-59.e1. Link: https://bit.ly/3wJ23fo

6. Fehime BA, Ayer M, Serteser M, Coskun A, Unsal I (2014) A Triclonal Gammopathy in a Relapsing Multiple Myeloma Patient, Detected by Immunosubstraction Method. Ann Clin Biochem 51: 606-610. Link: https://bit.ly/3B9Tj5j

7. Grosbois B, Jégo P, de Rosa H, Ruelland A, Lancien G, et al. (1997) Gammapathie Triclonale et Syndrome Immunoproliferatif Malin. Rev Med Interne 18: 470-473. Link: https://bit.ly/2UP4bVF

8. Vangsted A, Mikkelsen LH, Jørgensen JS, Heegaard S (2020) Lymphoplasmacytic lymphoma infiltrating both lacrimal glands in a patient with Waldenström's macroglobulinemia. Am J Ophthalmol Case Rep 17: 100597. Link: https://bit.ly/2Uk4p7d

9. Ray R, Schotters SB, Jacobs A, Rodgerson DO (1986) Triclonal Gammopathy in a Patient with Plasma Cell Dyscrasia. Clinical Chemistry 32: 205-207. Link: https://bit.ly/3kpdMx9

10. McKenna R, Kroft SH (2010) Sternberg's Diagnostic Surgical Pathology, $5^{\text {th }}$ Ed, 2010. Hematopoietic and Lymphatic Systems- Disorders of Bone Marrow. Chapter 16: 664.

Copyright: @ 2021 Maingrette M, et al. This is an open-access article distributed under the terms of the Creative Commons Attribution License, which permits unrestricted use, distribution, and reproduction in any medium, provided the original author and source are credited. 